\title{
Decoupling marine export production from new production
}

\author{
Gian-Kasper Plattner, Nicolas Gruber, Hartmut Frenzel, and James C. McWilliams \\ Institute of Geophysics and Planetary Physics, University of California, Los Angeles, USA
}

Received 7 February 2005; revised 13 May 2005; accepted 18 May 2005; published 14 June 2005.

[1] We investigate the relationship between annually integrated new and export production for the central Californian marine upwelling system using an eddyresolving coupled physical-ecosystem-biogeochemical model. We find that when averaged over the annual cycle lateral transport leads to a substantial spatial decoupling of export from new production, with a length-scale of decoupling on the order of $300 \mathrm{~km}$. The decoupling is largely caused by mean horizontal fluxes induced by persistent meso- and submesoscale circulation structures and to a lesser degree by the mean lateral offshore transport induced by Ekman transport. This indicates that the concept of numerically equal new and export production has to be used with great care, particularly in dynamic oceanic environments. Citation: Plattner, G.-K., N. Gruber, H. Frenzel, and J. C. McWilliams (2005), Decoupling marine export production from new production, Geophys. Res. Lett., 32, L11612, doi:10.1029/2005GL022660.

\section{Introduction}

[2] An important paradigm that has guided the biological oceanographic community over the last three decades is that new production can be equated with export production when averaged over appropriate spatial and temporal scales [Eppley and Peterson, 1979]. Export production is the net vertical transport of organic matter out of the euphotic zone. New production, $N P$, is that part of primary production fueled by the biological uptake of inorganic nitrogen supplied from outside the euphotic zone, $J_{B i o}\left(\mathrm{~N}_{n}\right)$ [Dugdale and Goering, 1967; Williams et al., 1989], and in steady state is equal to the sum of all mechanisms supplying inorganic nitrogen to the euphotic zone, i.e.

$$
N P=J_{B i o}\left(\mathrm{~N}_{n}\right)=\nabla \mathrm{NO}_{3}^{-}+\nabla \mathrm{NH}_{4}^{+}+J_{\mathrm{N}_{F i x}}+J_{\text {Others }},
$$

where $\nabla \mathrm{NO}_{3}^{-}$and $\nabla \mathrm{NH}_{4}^{+}$are the net transport divergences of $\mathrm{NO}_{3}^{-}$and $\mathrm{NH}_{4}^{+}$in the euphotic zone, $J_{\mathrm{N}_{F X}}$ is $\mathrm{N}_{2}$-fixation, and $J_{\text {Others }}$ represents the sum of all other external processes supplying inorganic nitrogen, such as atmospheric deposition and riverine inputs. $\mathrm{NO}_{3}^{-}$supply by upwelling and mixing of thermocline water is the most important source of inorganic nitrogen to the euphotic zone. Upwelling of $\mathrm{NH}_{4}^{+}$, mainly generated by remineralization processes just below the euphotic zone, $\mathrm{N}_{2}$-fixation, and other external processes are generally considered minor [Dugdale and Goering, 1967], but can be substantial under specific circumstances.

[3] The assumed equivalence of export and new production has permitted biogeochemists to use the comparably large number of estimates of new production as substitutes

Copyright 2005 by the American Geophysical Union. 0094-8276/05/2005GL022660\$05.00 for the often more scarce and difficult measurements of export production [Laws et al., 2000; Buesseler, 1998], which represents one of the key properties of interest for the global carbon cycle [Ducklow, 2001; Falkowski et al., 2003].

[4] However, export production can become spatially decoupled from new production because some fraction of the newly produced organic nitrogen can be transported laterally before leaving the euphotic zone, a process known to be particularly important in coastal upwelling systems [Berger et al., 1989]. Therefore, export production, EP, and new production, $N P$, are only numerically equivalent in steady state when the horizontal transport divergence of organic nitrogen, $\nabla_{h} \mathrm{~N}_{\text {org }}$, is considered, i.e.

$$
E P=N P-\nabla_{h} \mathrm{~N}_{\text {org }} .
$$

[5] The concept of Eppley and Peterson [1979] thus only applies if the averaging is done over a spatial scale that renders horizontal transport negligible relative to vertical export [Eppley, 1989; Falkowski et al., 2003]. Little is known about the length-scale over which this averaging has to be done. Moreover, observational limitations have forced investigators to often neglect this spatial averaging and assume that export production is equal to new production locally [Laws et al., 2000].

[6] We investigate here the relationship between new production and export production in the California Current System (CCS), using a high-resolution oceanic model. We address in particular the importance of lateral transport induced by persistent meso- and submesoscale features in decoupling these two production terms and provide an estimate of the horizontal scale of this decoupling.

\section{Model and Methods}

[7] We use an eddy-resolving coupled physical-ecosystem-biogeochemical oceanic model of the U.S. West Coast as described and evaluated in detail by N. Gruber et al. (Simulation of plankton ecosystem dynamics and upper ocean biogeochemistry in the California Current system, part 1: Model description, evaluation, and ecosystem structure, submitted to Deep-Sea Research, Part I, 2005, hereinafter referred to as Gruber et al., submitted manuscript, 2005). The circulation model is based on the Regional Oceanic Modeling System (ROMS) [Shchepetkin and McWilliams, 2005] and configured for the U.S. West Coast using a parent grid covering the entire domain at $15 \mathrm{~km}$ resolution and a $5 \mathrm{~km}$ resolution child grid covering just the central California upwelling region [Marchesiello et al., 2003]. It is run to quasi-equilibrium under climatological mean forcing (COADS [da Silva et al., 1994]). To remove small interannual variations due to intrinsic variability, we generally show and discuss 5-year averages. 

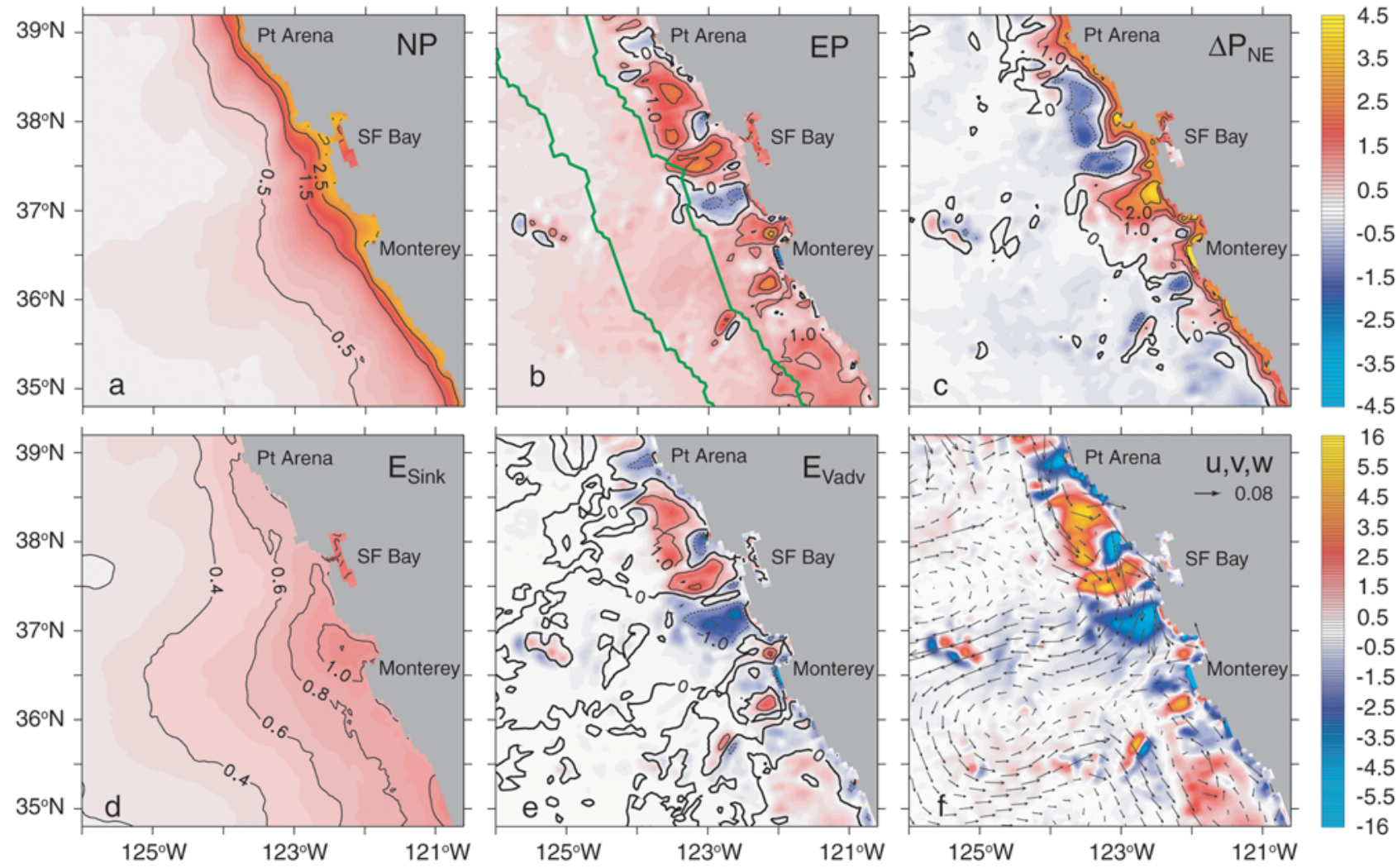

Figure 1. Spatial pattern and mechanisms of decoupling. Annual mean (a) euphotic zone new production, $N P$, (b) export production, $E P$, (c) decoupling of $N P$ and $E P, \Delta P_{N E}=N P-E P$, (d) export of organic nitrogen by sinking, $E_{\text {Sink }}$, (e) export of organic nitrogen by vertical advection, $E_{V a d}$, and (f) vertical transport velocities at the bottom boundary of the euphotic zone ( $w$; color) and horizontal velocities averaged over the euphotic zone depth $(u, v$; arrows). The solid green lines in Figure $1 \mathrm{~b}$ delineate the $80 \mathrm{~km}$ and $200 \mathrm{~km}$ offshore regions referred to in the main text. Upward directed fluxes and velocities are negative and downward directed fluxes and velocities are positive. The upper key applies to Figures 1a-1e with units of mol N m $\mathrm{yr}^{-1}$, whereas the lower key applies only to the vertical velocities in Figure $1 \mathrm{f}$ with units of $\mathrm{m} \mathrm{d}^{-1}$. Horizontal velocities in Figure $1 \mathrm{f}$ are in $\mathrm{m} \mathrm{s}^{-1}$.

[8] The ecosystem-biogeochemical model is a classical nitrogen-based, single-phytoplankton functional group, single-zooplankton, detrital-pool model (a so-called NPDZ model). Sinking is allowed for phytoplankton $(P)$, a small $\left(D_{S}\right)$ and a large $\left(D_{L}\right)$ detritus pool, but not for zooplankton $(Z)$. While sinking plays a major role in the dynamics of $D_{L}$, contributing substantially to the vertical export of organic matter, it is less important for $P$ and $D_{S}$, as these two pools behave primarily as suspended particulate pools. The biological parameters for the model have been set to represent typical plankton communities in upwelling coastal regions. The euphotic zone is calculated as the $1 \%$ light level, and extends to an average depth of between $34 \mathrm{~m}$ and $108 \mathrm{~m}$ in our focus area. $\mathrm{N}_{2}$-fixation, riverine inputs, and atmospheric deposition of inorganic nitrogen are not considered. Therefore new production in our model is equal to the sum of the net transport divergences of $\mathrm{NO}_{3}^{-}$and $\mathrm{NH}_{4}^{+}\left(\nabla \mathrm{NO}_{3}^{-}\right.$and $\nabla \mathrm{NH}_{4}^{+}$; see equation (1)).

[9] A detailed evaluation of the simulated fields with in situ and remotely sensed physical, biological and biogeochemical properties from AVHRR, SeaWiFS, CalCOFI, and the MBARI program suggests that the model captures the large-scale, time averaged pattern and their seasonal evolution in the eutrophic upwelling system of the CCS remarkably well [Marchesiello et al., 2003; Gruber et al., submitted manuscript, 2005]. The model correctly reproduces the SeaWiFS observed magnitude, seasonality, and offshore scale of the chlorophyll distribution in surface waters in the central upwelling zone [Gruber et al., submitted manuscript, 2005]. The offshore extension of chlorophyll associated with mesoscale circulation features such as eddies, jets, and filaments agrees very well with the zonal mesoscale spatial range of 100 to $150 \mathrm{~km}$ estimated for the CCS by Doney et al. [2003] using SeaWiFS ocean color. Averaged new production during the upwelling season is in good agreement with new production from shipboard measurements and with estimates derived from satellite data for the Point Conception upwelling center [Dugdale et al., 1997].

\section{Pattern and Length-Scale of Decoupling}

[10] We find a substantial spatial decoupling of export from new production, with the largest magnitude of the decoupling occurring in the very dynamic nearshore region (Figure 1). However, instead of continuously decreasing with distance from shore as expected from a maximum of upwelling nearshore and ensuing Ekman-driven lateral offshore transport [Berger et al., 1989], the decoupling exhibits substantial spatial heterogeneity. 


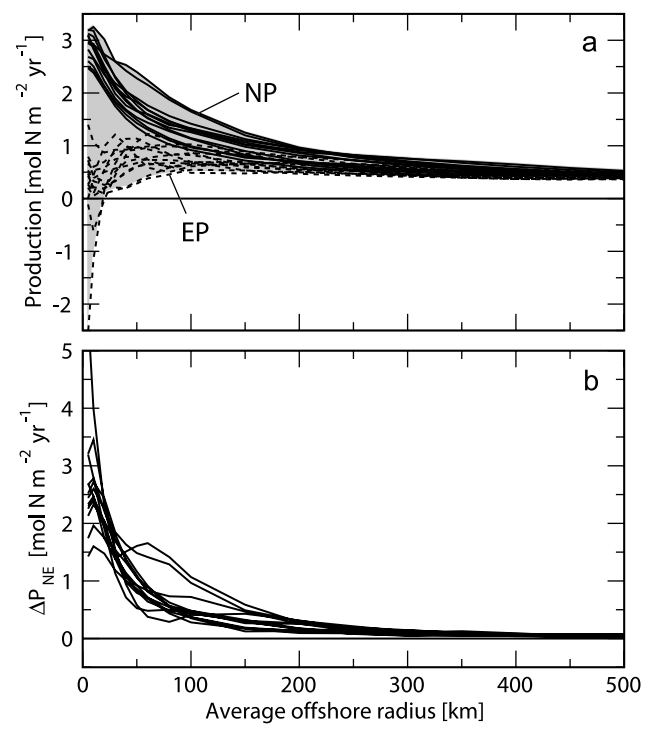

Figure 2. Length-scale of decoupling. Annual mean, spatially averaged offshore profiles of (a) euphotic zone new production $(N P$; solid) and export production $(E P$; dashed), and (b) decoupling of $N P$ and $E P, \Delta P_{N E}=N P-$ $E P$. The spatial averages are calculated over 13 circular regions with increasing radius, i.e., distance from coast.

[11] The annual mean distribution of new production integrated over the euphotic zone depth shows a relatively smooth onshore-offshore gradient (Figure 1a), driven by upwelling along the coast and the related vertical supply of $\mathrm{NO}_{3}^{-}$from below. The supply of $\mathrm{NH}_{4}^{+}$from just below the euphotic zone modifies new production somewhat, particularly nearshore where it contributes up to $18 \%$ of new production, but is otherwise small.

[12] In contrast, the annual mean export production shows a much more variable pattern (Figure 1b). Export production is positive when the sum of all vertical transport terms (i.e. vertical sinking, advection and diffusion) yields a net flux of organic nitrogen out of the euphotic zone. Local maxima and minima of export production occur somewhat offshore between about 10 and $80 \mathrm{~km}$ distance from the coast. Further offshore, export production decreases with a gradient similar to new production.

[13] Annual mean differences between new and export production, $\Delta P_{N E}$, are large and spatially heterogeneous (Figure 1c). While maximum differences are restricted to the upwelling zone within $30 \mathrm{~km}$ distance from the coast, substantial $\Delta P_{N E}$ extends to well over $100 \mathrm{~km}$ offshore.

[14] We determine a length-scale of decoupling on the order of $300 \mathrm{~km}$ (Figure 2), representing the appropriate offshore averaging distance necessary to ensure equivalence of mean export and new production in the CCS.

[15] Interestingly, this length-scale is not substantially different for results from a simulation with reduced horizontal model resolution (15 km; not shown), despite largely reduced eddy kinetic energy in the system [Marchesiello et al., 2003]. This length-scale is also robust with regard to details of the ecological model and its parameter choices. Additional model simulations with drastically different $Z$ grazing rates and $P$ mortality yielded essentially the same length-scale despite largely changed new and export production.
[16] The length-scale of decoupling is substantially larger than the above mentioned mesoscale spatial decorrelation length-scale of chlorophyll [Doney et al., 2003]. Because these two length-scales were defined differently, they can not be compared directly. Nevertheless, the difference also reflects that biomass variations and fluxes are only loosely coupled in the ocean. It is therefore not straightforward to infer variations in new and export fluxes from chlorophyll variations.

\section{Mechanisms of Decoupling}

[17] As evident from equation (2), the decoupling of new and export production is caused by the horizontal transport divergence of organic nitrogen. This horizontal transport divergence of organic nitrogen is driven in part by the mean Ekman-induced offshore transport, but includes a substantial component driven by persistent meso- and submesoscale features leading to large spatial heterogeneity (Figure 1c). The nearshore is a region of net horizontal divergence of organic nitrogen, consisting mainly of locally produced $P$ (not shown). In the offshore regions, horizontal divergence is about equally distributed between $P$ and $D_{S}$, as these two pools have very similar abundances in our model setup [Gruber et al., submitted manuscript, 2005]. The organic nitrogen that is laterally advected offshore is eventually removed out of the euphotic zone by either sinking or vertical advection.

[18] The sinking flux of organic nitrogen, mostly associated with $D_{L}$, shows a smooth onshore-offshore gradient with the highest values nearshore (Figure 1d). The pattern resembles new production, but is very different from export production within about $80 \mathrm{~km}$ distance from the coast. The sinking flux is on average $20 \%$ lower than new production

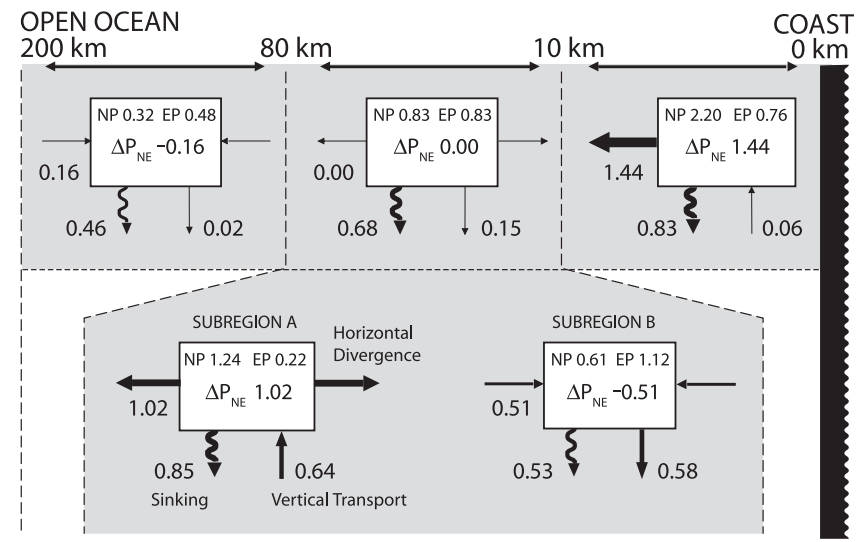

Figure 3. Annual mean euphotic zone budgets of organic nitrogen for different offshore regions. New production, $N P$, export production, $E P$, and decoupling of $N P$ and $E P$, $\Delta P_{N E}=N P-E P$, are given for each box. In steady state, $N P$ has to be balanced by the sum of horizontal divergence, vertical transport and vertical sinking of organic nitrogen. The upper three panels show budgets over the entire alongshore domain between $34.5^{\circ} \mathrm{N}$ and $40^{\circ} \mathrm{N}$. The budgets for subregions A $\left(36.4\right.$ to $\left.37.4^{\circ} \mathrm{N}\right)$ and $\mathrm{B}\left(37.5\right.$ to $\left.38.5^{\circ} \mathrm{N}\right)$ are examples of regions with large decoupling of export from new production in the 10 to $80 \mathrm{~km}$ band. Units are $\mathrm{mol} \mathrm{N} \mathrm{m} \mathrm{yr}^{-1}$. 
nearshore and by $45 \%$ higher than new production offshore. This highlights the importance of Ekman-driven lateral offshore transport of organic nitrogen in upwelling systems [Berger et al., 1989]. However, the sinking flux only accounts for a portion of export production in the nearshore zone.

[19] Vertical advection of organic nitrogen, predominantly associated with $P$ and $D_{S}$, exhibits a spatial heterogeneity that by magnitude and pattern is similar to the distribution of export production out to $80 \mathrm{~km}$ offshore (Figure 1e). Standing eddies and filaments cause large horizontal divergences and convergences, which in turn lead to strong vertical compensatory velocities and vertical organic nitrogen fluxes (Figure 1f). A large fraction of the laterally transported organic nitrogen in the nearshore zone of the CCS is thus exported out of the euphotic zone by vertical advection. The export of organic nitrogen by vertical diffusion (not shown) is found to be less than $1 \%$ of total export on average.

[20] The overall picture that emerges for the central California upwelling system is summarized by the organic nitrogen budgets shown in Figure 3 . Next to the coastline $(0$ to $10 \mathrm{~km}), \Delta P_{N E}$ is large as the upwelling leads to high biological productivity and large lateral offshore transport of organic nitrogen. Moving offshore, new production and export production decrease as does $\Delta P_{N E}$. Between 10 and $80 \mathrm{~km}$ offshore, persistent meso- and submesoscale features substantially influence the organic matter balance. While the budget for the entire alongshore region between $34.5^{\circ}$ to $40^{\circ} \mathrm{N}$ conforms to the picture of a mainly Ekman-driven decoupling (Figure 3, top middle), budgets over smaller subregions show substantial vertical advection and horizontal divergence terms that contribute to a total net gain/loss of organic nitrogen (Figure 3, bottom). Further offshore, the system resembles the open ocean, with small advective transport terms, export dominated by particle sinking, and generally low productivity.

\section{Summary and Conclusions}

[21] Vertical and horizontal transports associated with coastal upwelling, eddies, filaments and other mesoscale phenomena along the central Californian coast lead to a substantial decoupling of export from new production in the annual mean, with a length-scale on the order of $300 \mathrm{~km}$. The decoupling exhibits large spatial heterogeneity, caused by Ekman-driven offshore transport of organic nitrogen and persistent mesoscale circulation features. In this dynamic coastal environment the export of organic nitrogen out of the euphotic zone is a complex composite of sinking, vertical transport, and mixing.

[22] Our results indicate that even in a steady state situation, the concept of numerically equal new and export production has to be used with great care. Given the large spatial heterogeneity present in the coastal system, neither local long-term nor large-scale short-term measurements of new production result in a good estimate of export produc- tion. The consequence is somewhat bleak in that an accurate determination of export production from new production in such dynamic systems requires long-term and large-spatial scale measurements, which has clearly practical limitations. This challenge can only be met, in our opinion, by optimally combining in situ and remotely obtained measurements with detailed high-resolution coupled physical-ecosystem-biogeochemical models to put these limited observations into a broader spatial and temporal context.

[23] Acknowledgments. This work was funded by NASA (Grant NASA-NNG04GJ89G). GKP was granted support by a Global and Climate Change fellowship from NOAA. Computing time at NCSA is acknowledged. We appreciate the comments by two anonymous reviewers.

\section{References}

Berger, W. H., V. S. Smetacek, and G. Wefer (1989), Ocean productivity and paleoproductivity-An overview, in Productivity of the Ocean: Present and Past, edited by W. H. Berger, V. S. Smetacek, and G. Wefer, pp. 1-35, John Wiley, Hoboken, N. J.

Buesseler, K. O. (1998), The decoupling of production and particulate export in the surface ocean, Global Biogeochem. Cycles, 12(2), 297310

da Silva, A. M., C. C. Young-Molling, and S. Levitus (Eds.) (1994), Atlas of Surface Marine Data 1994, vol. 1, Algorithms and Procedures, NOAA Atlas NESDIS, vol. 6, 83 pp., NOAA, Silver Spring, Md

Doney, S. C., D. M. Glover, S. J. McCue, and M. Fuentes (2003), Mesoscale variability of Sea-viewing Wide Field-of-view Sensor (SeaWiFS) satellite ocean color: Global patterns and spatial scales, J. Geophys. Res., 108(C2), 3024, doi:10.1029/2001JC000843

Ducklow, H. W. (2001), Upper ocean carbon export and the biological pump, Oceanography, 14(4), 50-58.

Dugdale, R. C., and J. J. Goering (1967), Uptake of new and regenerated forms of nitrogen in primary productivity, Limnol. Oceanogr., 12, 196206.

Dugdale, R. C., C. O. Davis, and F. P. Wilkerson (1997), Assessment of new production at the upwelling center at Point Conception, California, using nitrate estimated from remotely sensed sea surface temperature, J. Geophys. Res., 102(C4), 8573-8585.

Eppley, R. W. (1989), New production: History, methods, problems, in Productivity of the Ocean: Present and Past, edited by W. H. Berger, V. S. Smetacek, and G. Wefer, pp. 85-97, John Wiley, Hoboken, N. J. Eppley, R. W., and B. J. Peterson (1979), Particulate organic matter flux and planktonic new production in the deep ocean, Nature, 282, 677-680.

Falkowski, P. G., E. A. Laws, R. T. Barber, and J. W. Murray (2003), Phytoplankton and their role in primary, new, and export production, in Ocean Biogeochemistry: The Role of the Ocean Carbon Cycle in Global Change (a JGOFS Synthesis), edited by M. Fasham et al., pp. 99-121, Springer, Berlin.

Laws, E. A., P. Falkowski, H. Ducklow, W. O. Smith Jr., and J. J. McCarthy (2000), Temperature effects on export production in the open ocean, Global Biogeochem. Cycles, 14(4), 1231-1246.

Marchesiello, P., J. C. McWilliams, and A. Shchepetkin (2003), Equilibrium structure and dynamics of the California Current system, J. Phys. Oceanogr., 33, 753-783

Shchepetkin, A. F., and J. C. McWilliams (2005), The regional oceanic modeling system (ROMS): A split-explicit, free-surface, topographyfollowing-coordinate oceanic model, Ocean Modell. IX, pp. 347-404, Hooke Inst. Oxford Univ., Oxford, U. K.

Williams, P. J. L., et al. (1989), Group report: Export productivity from the photic zone, in Productivity of the Ocean: Present and Past, edited by W. H. Berger, V. S. Smetacek, and G. Wefer, pp. 99-115, John Wiley, Hoboken, N. J.

H. Frenzel, N. Gruber, J. C. McWilliams, and G.-K. Plattner, Institute of Geophysics and Planetary Physics, University of California, 5839 Slichter Hall, Los Angeles, CA 90095, USA. (plattner@igpp.ucla.edu) 